Association for Information Systems AIS Electronic Library (AISeL)

MWAIS 2009 Proceedings

Midwest (MWAIS)

$5-2009$

\title{
Generating User Stories in Groups
}

Aaron Read

University of Nebraska Omaha, aread@mail.unomaha.edu

Erin Gallagher

University of Nebraska Omaha, egallagher@mail.unomaha.edu

Cuong Nguyen

University of Nebraska Omaha, cdnguyen@mail.unomaha.edu

Gert-Jan de Vreede

University of Nebraska Omaha, gdevreede@usf.edu

Follow this and additional works at: http://aisel.aisnet.org/mwais2009

\section{Recommended Citation}

Read, Aaron; Gallagher, Erin; Nguyen, Cuong; and de Vreede, Gert-Jan, "Generating User Stories in Groups" (2009). MWAIS 2009

Proceedings. 29.

http://aisel.aisnet.org/mwais2009/29

This material is brought to you by the Midwest (MWAIS) at AIS Electronic Library (AISeL). It has been accepted for inclusion in MWAIS 2009

Proceedings by an authorized administrator of AIS Electronic Library (AISeL). For more information, please contact elibrary@aisnet.org. 


\title{
Generating User Stories in Groups
}

\author{
Aaron S. Read \\ University of Nebraska Omaha \\ aread@mail.unomaha.edu \\ Cuong D. Nguyen \\ University of Nebraska Omaha \\ cdnguyen@mail.unomaha.edu
}

\author{
Erin Gallagher \\ University of Nebraska Omaha \\ egallagher@mail.unomaha.edu \\ Gert-Jan de Vreede
University of Nebraska Omaha
gdevreede@mail.unomaha.edu
}

\begin{abstract}
User stories allow customers to easily communicate desired specifications as part of Agile Software Development methods. When elicited from groups instead of individuals, the number of stories generated and the comprehensiveness of the stories is likely to increase. We present a 2 X 2 study design involving group vs. individual user story brainstorming with one or two sentence vs. unlimited user story length.
\end{abstract}

\section{Keywords}

Requirements elicitation, user stories, collaboration, group storytelling

\section{INTRODUCTION}

Software development remains a challenging process with nearly half of the projects considered late, over budget, and completed with fewer features than planned (Rubenstein 2007). Poorly defined requirements are considered to be a leading factor in project failure (Hofmann and Lehner 2001). Agile software development methodologies address difficulties of developing requirements resulting from rapidly changing customer needs by allowing a development team to respond quickly to changing requirements (Highsmith and Cockburn 2001). They encourage incremental releases, cooperation between customer and developers, simplicity (ease of learning), and adaptivity (Abrahamsson, Warsta, Siponen and Ronkainen 2003). User stories are an integral part of several Agile methodologies including XP and Scrum (Beck and Fowler 2000; Cohn 2004). A user story is an account in the user's own words of a way that (s)he would like to use the software and enables the communication of software requirements without needing familiarity with a specific method of delivery or jargon (Cohn 2004). While using stories as a means of gathering requirements has been shown to be beneficial in a number of studies (Alvarez and Urla 2002; Ima and Benyon 1999; Sutcliffe 2003), collecting system requirements in the form of user stories can also be problematic for several reasons: A customers' tacit knowledge may be partially hidden, stories are subject to multiple interpretations and personal bias, and the completeness of the set of stories is difficult to determine (Sutcliffe 2003). These problems may be addressed by collecting stories in groups. Group story telling can create an environment that supports evaluation of experience and promotes problem-solving (Banks-Wallace 1998). This can help surface conflicts in goals among users and enable them to create shared understanding. Group story telling can also help elicit the tacit knowledge of participants with the richness of several different perspectives (Valle, Prinz and Borges 2002).

The purpose of our research is to understand how group generated stories differ from those generated by individuals. A key criterion to assess the quality of a set of requirements is completeness, with a minimal amount of conflicts and overlaps in requirements (Grünbacher, Halling, Biffl, Kitap and Boehm 2004). We therefore compare individual and group storytelling in terms of the level of completeness and lack of overlaps or conflicts in requirements.

In the following section we define stories and explain their use in software engineering. We then explain the design of our study. The paper concludes with a discussion of the envisioned contributions and expected challenges regarding the further execution of the study.

\section{BACKGROUND}

User stories are narratives retelling personal experience (Creswell 2006). Stories help to assist in making sense of our experiences (Bell 2002). In software engineering, stories are used and structured in at least two different ways. First, stories may be used as a means of understanding the experiences and needs of users. They can capture the experiences of users with a current system as well as aid in capturing the desired attributes of a system (Alvarez et al. 2002). In Agile Software development stories are structured in a way that helps stakeholders to easily relate essential details of software requirements for a new system. Stories must focus on the experience of the user and must be short enough to fit on an index card (Cohn 
2004; Jeffries, Anderson and Hendrickson 2000). These short stories are then used as conversation starters with developers who confirm the details of the story in acceptance tests on the software (Jeffries et al. 2000).

Eliciting requirements in the form of user stories allows stakeholders to convey their needs in a way that is natural to them, allowing them to relate more tacit knowledge (Alvarez et al. 2002). Details of stories are worked out between developer and customer through oral communication, thus avoiding errors of interpretation which may occur with written requirements (Jeffries et al. 2000).

When stories are collected from individuals, valuable information might not be volunteered by users as they might assume it is already known to the requirements engineers, or forget abnormal cases (Sutcliffe, 2003). Allowing users to generate stories in groups can alleviate some of the aforementioned shortcomings of collecting user requirements with stories individually. Story telling in groups allows a problem to be seen from multiple perspectives (Valle et al. 2002). When users tell stories in groups, the knowledge of one user can be expanded by another user, since the knowledge of one user helps to activate the knowledge of another group member (Leal 1993).

With this understanding of the benefits of group storytelling, we propose to test the following hypotheses:

There will be a main effect of group composition on story quantity, comprehensiveness, and uniqueness such that individuals working in groups will generate:

H1: A larger quantity of stories than individuals working alone,

H2: More comprehensive stories than individuals working alone,

H3: More unique stories than individuals working alone.

We will also be testing whether or not story length (one to two sentence or unlimited story length) affects these dependent variables and whether or not there are any interactive effects between the independent variables on the dependent variables. As this is an exploratory study, we would like to test whether or not the more structured user story form used in XP (Beck et al. 2000) benefits users in transferring the desired attributes of a system.

\section{METHODS}

\section{Participants}

Participants will be 84 voluntary college students recruited from a Midwestern university. Course credit or extra credit may be awarded for some subjects. Random assignment will be implemented to ensure participants are evenly distributed across treatment groups. Gender and racial representation is expected to be consistent with the proportion of the population at the university.

\section{Independent Variables}

Group Composition. Participants will generate stories either individually or in a small group. In the individual treatment group, three individuals will generate user stories for a text book exchange system by themselves. In the group condition participants will be randomly assigned to a group of three individuals to generate user stories.

Story Length. Participants will be informed that they should provide descriptions either in one or two sentences or be told that there is no limit on how long the description of features they provide.

\section{Dependent Variables}

Quantity. The number of requirements coded from user stories generated by subjects

Comprehensiveness. The comprehensiveness of the requirements coded from user stories will be assessed in a manner similar to Pitts and Browne (2007). Comprehensiveness is determined by the number of predetermined categories covered by the requirements generated (breadth) as well as the number of requirements in each category (depth).

Uniqueness. Story uniqueness is the extent to which stories generated do not overlap or duplicate the functionality of other stories generated.

Additional Measures. Participants will complete additional measures assessing their perceptions and attitudes towards the story generation process, including demographic information, satisfaction with the process, understanding of the generated stories, and level of agreement regarding the generated stories. 


\section{Design}

This study employs a $2 \times 2$ between-participants factorial design composed of two factors each at two levels: group composition (individual versus 3-person group), and story length (Two sentence story versus no length requirement).

After providing a brief introduction explaining the purpose of the research, participants will provide consent and be randomly assigned to one of the experimental conditions. Participants will then complete a brief demographic questionnaire and receive answers to any questions they may have. The session will begin with a script read to subjects providing a description of the project as well as delineating the task required of the subjects. A sample script can be seen in Appendix A. All conditions will last 40 minutes. Following completion of the story generation task, all individuals will complete additional measures and receive debriefing.

\section{Plan of Analyses}

Descriptive statistics and correlations will be calculated for all variables of interest, as well as tests of univariate and multivariate normality. T-tests will be conducted to test for differences in group composition as a function of demographic variables, as well as to test for main effects of the manipulated independent variables on the dependent variables. Hypothesized interactions will be tested using ANOVA.

\section{DISCUSSION}

This research in progress describes how we will explore whether or not generating user stories in groups will result in a significantly more numerous and more comprehensive set of user stories. We will also understand the benefit of limiting story length and structuring user stories. Such understanding will provide insight for practitioners and researchers wishing to understand the benefits of group storytelling in the requirements elicitation setting. Creating this research design is not without challenges. We hope to assure that the user story generating task is fair between individuals and groups. We also need to be certain that our instructions are clear enough so that non-information systems majors can accomplish the task.

\section{REFERENCES}

1. Abrahamsson, P., Warsta, J., Siponen, M.T., and Ronkainen, J. "New directions on agile methods: a comparative analysis," IEEE Computer Society, Portland, Oregon, 2003, pp. 244-254

2. Alvarez, R., and Urla, J. "Tell me a good story: using narrative analysis to examine information requirements interviews during an ERP implementation," SIGMIS Database (33:1) 2002, pp 38-52

3. Banks-Wallace, J. "Emancipatory Potential of Storytelling in a Group," Journal of Nursing Scholarship (30:1) 1998, pp $17-22$

4. Beck, K., and Fowler, M. Planning Extreme Programming Addison-Wesley Longman Publishing Co., Inc., 2000, p. 160

5. Bell, J.S. "Narrative Inquiry: More Than Just Telling Stories," TESOL Quarterly (36:2) 2002, pp 207-213

6. Cohn, M. User Stories Applied: For Agile Software Development Addison Wesley Longman Publishing Co., Inc. , 2004.

7. Creswell, J.W. Qualitative Inquiry and Research Design: Choosing among Five Approaches. Second Edition SAGE Publications Thousand Oaks, CA, 2006.

8. Grünbacher, P., Halling, M., Biffl, S., Kitap, H., and Boehm, B.W. "Integrating Collaborative Processes and Quality Assurance Techniques: Experiences from Requirements Negotiation," Journal of Management Information Systems (20:4) 2004, pp 9-29

9. Highsmith, J., and Cockburn, A. "Agile software development: the business of innovation," Computer (34:9) 2001, pp $120-127$.

10. Hofmann, H.F., and Lehner, F. "Requirements Engineering as a Success Factor in Software Projects," IEEE Software (18:4) 2001, pp 58-66.

11. Ima, M., and Benyon, D. "How Stories Capture Interactions," IOS Press, 1999.

12. Jeffries, R.E., Anderson, A., and Hendrickson, C. Extreme Programming Installed Addison-Wesley Longman Publishing Co., Inc., 2000, p. 288

13. Leal, D.J. "The Power of Literary Peer-Group Discussions: How Children Collaboratively Negotiate Meaning," Reading Teacher (47:2) 1993, pp 114-120.

14. Pitts, M.G., and Browne, G.J. "Improving requirements elicitation: an empirical investigation of procedural prompts," Information Systems Journal (17:1) 2007, pp 89-110

15. Rubenstein, D. "Standish Group Report: There's Less Development Chaos Today," in: Software Development Times, 2007.

16. Sutcliffe, A. "Scenario-based requirements engineering," in: Requirements Engineering Conference, 2003. Proceedings. 11th IEEE International, 2003, pp. 320-329. 
17. Valle, C., Prinz, W., and Borges, M. "Generation of group storytelling in post-decision implementation process," in: Computer Supported Cooperative Work in Design, 2002. The 7th International Conference on, 2002, pp. 361-367. 


\section{APPENDIX A}

\section{Experiment Scripts}

Every subject in the groups will be given the same overview description of the system to be designed as follows:

The Book Exchange is a website which will be designed to allow students at this university to buy and sell text books at a reasonable price. The website will not provide payment services; it will simply allow sellers to post items for sale, allowing potential buyers to search for their textbook offerings. The website will also have features that facilitate a buyer's search for textbooks. For example, the website will have access to which textbooks are required for a given course.

In the short user story treatment, the subjects receive the following instructions. In the treatment where user stories are not required, the experiment participants are encouraged only to provide stories about software requirements.

- Provide as many user stories as possible. A user stories is a story that provides a feature you think the system should have. A recommended form for a user story is:

"As a $<$ type of user $>$, I want $<$ some goal $>$ so that $<$ some reason $>$."

e.g. "As a buyer, I want to be able to see the prices of all the books so that I can decide whether to buy the book or not.

- Organize the stories into a given set of categories.

- Continue to brainstorm user stories

Your stories should not be more than two sentences in length. You are NOT being asked to come up with a technical description of the website (i.e., it will use mySQL database for data storage). Instead we are asking you to describe what the website can do from the perspective of the website's users.

The experiment will be conducted in one hour long sessions and the experiment processes applied to each of four treatment groups are as follows:

- Individual story telling - Unprompted group: For this group, the session starts with letting the subjects complete a questionnaire. After that, the investigators give a short presentation about the purpose and the procedure of the session. Then, the subjects are trained on using GroupSystems. Next each subject is required to generate his/her user stories individually, i.e. no contact with other subjects is allowed, by typing them in a computer. After that, the individuals reorganizes their stories by putting them into the appropriate prioritization category: critical, important, and if resources permit. Finally, each member in the group will spend a portion of the time generating additional user stories.

- Individual story telling -Prompted group: For this group, the session starts with letting the subjects complete a questionnaire. After that, the investigators give a short presentation about the purpose and the working process of the session. Then, the subjects are trained on using GroupSystems. Next each subject is required to generate his/her user stories individually, i.e. no contact with other subjects is allowed, by typing them in a computer. As the group brainstorms, prompts will be displayed relating to the overarching goals of the system. After that, the individuals reorganizes their stories by putting them into the appropriate prioritization category: critical, important, and if resources permit. Finally, each member in the group will spend a portion of the time generating additional user stories.

- Group story telling - Unprompted group: For this group, the session starts with letting the subjects complete a questionnaire. The subjects are requested to provide stories only one or two sentences in length. Then the subjects are divided into groups of three people. After that, the investigators give a short presentation about the purpose and the working process of the session. Then, the subjects are trained on using GroupSystems. Next, each subject group is required to generate their user stories together by contributing user stories to the same electronic page or list at the same time. After that, the group reorganizes their stories by putting them into the appropriate prioritization category: critical, important, and if resources permit. Finally, each member in the group will spend a portion of the time generating additional user stories.

- Group story telling - Prompted group: For this group, the session starts with letting the subjects complete a questionnaire. The subjects are requested to provide stories only one or two sentences in length. Then the subjects are divided into groups of three people. After that, the investigators give a short presentation about the purpose and the working process of the session. Then, the subjects are trained on using GroupSystems. Next, each subject group is required to generate their user stories together by contributing user stories to the same electronic page or list at the same time. As the group brainstorms, prompts will be displayed relating to the overarching goals of the system. After that, the group reorganizes their stories by putting them into the appropriate prioritization category: critical, important, and if resources permit. Finally, each member in the group will spend a portion of the time generating additional user stories. 